\title{
The utility of patient reported data in a gynecologic oncology clinic
}

\author{
D. Barnes ${ }^{1^{*}} \mathbb{D}$, R. Rivera', S. Gibson², C. Craig ${ }^{1}$, J. Cragun², B. Monk ${ }^{1}$ and D. Chase ${ }^{1}$
}

\begin{abstract}
Background: Measuring QoL is essential to the field of gynecologic oncology but there seems to be limited standardized data regarding collecting QoL assessments throughout a patient's cancer treatment especially in nonclinical trial patients. The aim of this study is to explore patient characteristics that may be associated with poor quality of life (QoL) in women with gynecologic cancers at two University of Arizona Cancer Center (UACC) sites.

Methods: A cross-sectional survey was conducted among English speaking women with gynecologic malignancies at the University of Arizona Cancer Centers in Phoenix and Tucson from April 2012 to July 2015. The survey was a paper packet of questions that was distributed to cancer patients at the time of their clinic visit. The packet contained questions on demographic information, treatment, lifestyle characteristics, pelvic pain and Health-related quality of life (HRQOL). Measures included the generic and cancer-specific scores on the Functional Assessment of Cancer TherapyGeneral (FACT-G) and the Female Genitourinary Pain Index (GUPI). The total scores and subdomains were compared with descriptive variables (age, body mass index (BMI), diet, exercise, disease status, treatment and support group attendance) using Cronbach alpha (a), Spearman rank correlations ( $\rho)$, and Holm's Bonferroni method.
\end{abstract}

Results: One-hundred and forty-nine women completed the survey; 55\% ( $N=81)$ were older than 60 years, $38 \%(N=45)$ were obese $(B M I>30), 46 \%(N=66)$ exercised daily, and $84 \%(N=111)$ ate one or more daily serving of fruit and vegetables. Women in remission, those who exercised daily and ate fruits/vegetables were less likely to have their symptoms impact their QoL. Younger women were more likely to report genitourinary issues $(p=-0.22)$ and overall problems with QoL $(p=-0.29)$ than older women. Among FACT-G support group responses, we found those that did not attend support groups had a significantly higher emotional wellbeing $(p=0.05)$.

Conclusions: This study identified potential areas of clinical focus, which aid in understanding our approach to caring for gynecologic cancer patients and improvement of their HRQoL. We identified that age, pelvic pain, and lifestyle characteristics have indicators to poor QoL in women with gynecologic cancers. In this population, younger women and those with pelvic pain complaints, poor diet and exercise habits should be targeted early for supportive care interventions to improve QoL throughout both treatment and survivorship.

\section{Background}

The impact of illness and treatment on quality of life (QoL) has received increasing recognition in recent years with the both the National Cancer Institute and the Food and Drug Administration who have mandated that the goals of cancer research should be to improve both survival and QoL [1]. Measuring QoL is essential to the field of gynecologic oncology but there seems to be limited standardized data regarding collecting QoL

\footnotetext{
* Correspondence: Nikky.barnes@gmail.com

'Department of Gynecologic Oncology, Creighton University School of Medicine at St. Joseph's Hospital and Medical Center, Phoenix, AZ, USA Full list of author information is available at the end of the article
}

assessments throughout a patient's cancer treatment especially in non-clinical trial patients $[2,3]$. Prior studies have demonstrated that a patient's QoL changes over the course of treatment; however this is unknown in non-clinical trial patients $[4,5]$.

QoL is defined as the level of satisfaction a person has with their physical (PWB), emotional (EWB), and social wellbeing (SWB) [6]. The diagnosis of cancer in a woman encompasses not only the physical effects of the disease but also the short and long-term side effects of treatment, its cost, potential economic loss, and the reaction of family and friends, each of which influence QoL [6-12]. Since QoL is a multidimensional concept it

(c) The Author(s). 2018 Open Access This article is distributed under the terms of the Creative Commons Attribution 4.0 International License (http://creativecommons.org/licenses/by/4.0/), which permits unrestricted use, distribution, and 
is important to assess how it affects various communities and populations so that interventions can be designed to help improve overall wellbeing in patients. Numerous instruments have been created and aim to measure patients' QoL [13]. One of these measures is the Health Related Quality of Life (HRQoL), which allows patients to self-report symptoms using patient-reported outcome (PRO) measures [4, 14]. The use of PRO, especially in oncology, has been shown to help with detection of problematic symptoms, symptom monitoring, satisfaction with patient care, and communication between clinicians and patients [15-17].

The aim of this study is to examine HRQoL in a community oncology setting. The goal of this research is to ultimately identify and then address areas to target QoL interventions in a non-clinical trial population.

\section{Methods}

\section{Study design}

Following Institutional Review Board approval, we performed a cross-sectional HRQoL survey among women aged 21-89 years with gynecologic malignancies (cervical, ovarian, and/or uterine) seen at the University of Arizona Cancer Center locations in Phoenix and Tucson from April 2012 to July 2015.

\section{Patient selection}

Participants were comprised of women who had survived cancer and were undergoing care at our two sites. Eligibility criteria included: 1) age $\geq 21$ years, 2) current gynecologic malignancy 3) current history of gynecologic malignancy 4) ability to read, write, and understand English (as a primary or secondary language). Women were excluded if they did not complete at least $50 \%$ of the questionnaire.

\section{QoL assessments and instruments}

We used a questionnaire packet that included the Functional Assessment of Cancer Therapy Female Genitourinary Pain Index, and self-reported demographic information. The QoL questionnaires were scored separately.

Functional Assessment of Cancer Therapy - General (FACT-G), is a 27-item QoL instrument that consisted of four well-being subscales: physical, functional, social, and emotional $[18,19]$. Within each subdomain, questions are answered on a 5-point Likert scale, ranging from 1 (not at all) to 4 (very much). The items are summed to give a score for each subdomain. The subdomain scores are then summed to give a total FACT score; higher subscale and total scores indicate better QoL [20].

The Genitourinary Pain Index (GUPI) is a 15-item instrument intended to measure, within the past week, the intensity of three constructs: (a) pelvic pain or discomfort, (b) urinary symptoms, and (c) quality of life [21]. Lower subscale and total scores indicate better QoL.
Construct A: Pelvic pain or discomfort was measured by ten items: eight of these items, which consisted of binary response options $(0=$ no, $1=$ yes $)$, were indicative of pain/discomfort stemming both from the pelvic area (e.g., urethra, vagina) and activities involving the pelvic area (e.g., sexual intercourse, urinating). The ninth item measured pelvic pain frequency with six-point response options ranging from 0 (never) to 5 (always), and the tenth item used an 11-point average pain scale ranging from 0 to 10 . The scores were summed to create a total score that could range from 0 to 23 .

Construct B: Urinary symptoms (e.g., urinating frequency) were measured with two GUPI items with response options that ranged from 0 (not at all) to 5 (almost always). The mean of the two items were computed creating a score ranging from 0 to 5 with higher scores being indicative of higher urinary symptoms.

Construct C: GUPI- QoL consisted of three items that measured the impact of the symptoms on decreasing respondent's QoL. The first two items have response options ranging from 0 (none) to 3 (a lot). The third item, which had response scale ranging from 1 (pleased) to 6 (terrible), measured how respondents felt about symptoms if they had them for the rest of their life. The three items were summed to create a total score, which could range from 1 to 12, with higher values being indicative of worse impact on QoL.

Self-reported demographic information such as age, weight, height, BMI, disease status (current disease verses cancer remission), cancer stage, past medical history, past surgical history, previous cancer treatment, and current chemotherapy treatment cycle was collected via self-reported questionnaire. The survey also included questions on exercise frequency (defined as $\geq 30 \mathrm{~min}$ of moderate activity), amount of daily consumption of fruits of vegetables, and support group attendance.

\section{Data collection}

Potential study participants were approached after registering for their appointment at a clinic visit, and the objective of the study was explained. If they choose to participate, they were given the questionnaire, and patients self-reported their answers. Informed consent was obtained and presumed when patients proceeded with the questionnaire. The self-administered survey took approximately $15-20$ min to complete.

\section{Study measures}

\section{Socio-demographic}

Descriptive statistics were calculated for demographic and clinical characteristics. Differences in demographic, clinical, and symptoms characteristics, as well as QoL outcomes, were evaluated using Cronbach alpha $(\alpha)$, 
Spearman rank correlations ( $\rho$ ), and Holm's Bonferroni method were used to correct for type-I error rates.

\section{Statistical analysis}

For each lifestyle behavior a one-way analysis of covariance was used to examine the association with HRQoL. Descriptive statistics and frequency distributions were performed while controlling for potential demographic and medical confounders for each lifestyle behavior. Logistic regression was then used for analysis with significance set at $p<0.05$.

\section{Results}

A total of 149 women participated in the study. Of the completed questionnaires $100 \%$ of patients completed the questions for age, $80 \%$ completed BMI and disease status, $88 \%$ completed diet questions, $97 \%$ completed questions for exercise, history of surgery, and support group attendance, $44 \%$ completed treatment questions, and $77 \%$ completed questions on their disease status.

Baseline self-reported demographics for the final analytic cohort are reported in Table 1. A little over half $(55.4 \%, N=81)$ of the women were older than 60 years, and over two-thirds $(68.6 \%, \mathrm{~N}=81)$ self-reported they were overweight or obese. About $46 \%$ reported exercising daily $(N=66)$ and $31 \%(N=45)$ exercised weekly.
Roughly $84 \%(N=111)$ had more than one daily serving of fruit and vegetables. Only $13 \%(N=19)$ of the women attended a support group.

Treatment, cancer stage, and disease status of the final analytic cohort are presented in Table 2. Prior treatment was defined as chemotherapy and/or surgery, and there were no documented treatments available for 23 individuals. Of the participants with documented treatment, 61 (48\%) had a history of receiving chemotherapy, while another $61(48 \%)$ were currently receiving chemotherapy. Only five (4\%) were re-initiating chemotherapy. Among the 61 women who had a previous chemotherapy, $56 \%$ had their last treatment less than a year prior to study participation. Of the 61 patients who were currently receiving chemotherapy, $82 \%$ were in the middle (cycles $2-5$ ) of their treatment cycle. The majority $(83 \%, N=120)$ of participants had either a recent or a historical report of surgery. Disease status was obtained from the questionnaires for 119 women and a little more than a quarter $(27 \%, N=32)$ had received their first chemotherapy dose, almost a third $(33 \%, N=39)$ had a recurrence of cancer, and $40 \%(N=48)$ were in remission. Among participants with a documented cancer stage $(N=114), 60 \%$ had stage III or IV disease.

Table 3 summarizes the Spearman's rho rank-order correlations $(\rho)$ of three GUPI subscales, as well as four

Table 1 Demographic Characteristics of Participant from April 2012 to July 2015 ( $N=149)$

\begin{tabular}{|c|c|c|c|}
\hline & & $F$ & $\%$ \\
\hline \multirow[t]{6}{*}{ Age (years) } & $21-40$ & 15 & 10.07 \\
\hline & $41-50$ & 19 & 12.75 \\
\hline & $51-60$ & 34 & 22.82 \\
\hline & $61-70$ & 50 & 33.56 \\
\hline & $>70$ & 31 & 20.81 \\
\hline & Total & 149 & 100 \\
\hline \multirow[t]{5}{*}{ BMI Categories $\left(\mathrm{kg} / \mathrm{m}^{2}\right)$} & Underweight (< 18.5) & 0 & 0.00 \\
\hline & Healthy (18.5-24.99) & 37 & 31.36 \\
\hline & Overweight (25-29.99) & 36 & 30.51 \\
\hline & Obese (30+) & 45 & 38.14 \\
\hline & Total & 118 & 100 \\
\hline \multirow[t]{4}{*}{ Exercise } & Never & 34 & 23.45 \\
\hline & Weekly & 45 & 31.03 \\
\hline & Daily & 66 & 45.52 \\
\hline & Total & 145 & 100 \\
\hline \multirow[t]{4}{*}{ Daily Amount of Fruit/ Vegetables (servings) } & $<1$ & 21 & 16.03 \\
\hline & $1-2$ & 68 & 51.91 \\
\hline & $\geq 3$ & 42 & 32.06 \\
\hline & Total & 131 & 100 \\
\hline \multirow[t]{3}{*}{ Attends Support Group } & Yes & 19 & 13.10 \\
\hline & No & 126 & 86.90 \\
\hline & Total & 145 & 100 \\
\hline
\end{tabular}


Table 2 Frequency and Percent Distribution of Historical/Current Treatment and Disease Progression from April 2012 to July 2015

\begin{tabular}{|c|c|c|c|}
\hline & & F & $\%$ \\
\hline \multirow[t]{6}{*}{ Last Previous Treatment } & $<1$ month & 13 & 19.70 \\
\hline & 2-6 month & 11 & 16.67 \\
\hline & $6-12$ & 13 & 19.70 \\
\hline & $13-24$ & 7 & 10.61 \\
\hline & $>2$ years & 22 & 33.33 \\
\hline & Total $^{\mathrm{a}}$ & 66 & 100 \\
\hline \multirow[t]{4}{*}{ Chemotherapy Cycle of Current Treatment } & First & 3 & 4.55 \\
\hline & Middle & 54 & 81.82 \\
\hline & Last & 9 & 13.64 \\
\hline & Total $^{a}$ & 66 & 100 \\
\hline \multirow[t]{3}{*}{ History / Recent Surgery } & Yes & 120 & 83.33 \\
\hline & No & 24 & 16.67 \\
\hline & Total & 144 & 100 \\
\hline \multirow[t]{4}{*}{ Disease Status } & 1st Chemotherapy Treatment & 32 & 26.89 \\
\hline & Recurrent & 39 & 32.77 \\
\hline & Remission & 48 & 40.34 \\
\hline & Total & 119 & 100 \\
\hline \multirow[t]{5}{*}{ Cancer Stage } & 1 & 25 & 21.93 \\
\hline & $\|$ & 20 & 17.54 \\
\hline & $\| I$ & 43 & 37.72 \\
\hline & IV & 26 & 22.81 \\
\hline & Total & 114 & 100 \\
\hline
\end{tabular}

${ }^{\mathrm{a}} 127$ participants had a record either of only a previous treatment $(n=66)$, only a current chemotherapy treatment $(n=66)$, and for 23 cases the treatment status was not known

FACT-G dimensions, with age, BMI, healthy behaviors, surgery, and disease status. Pelvic pain or discomfort was not correlated to patient's age, BMI, healthy behaviors (exercise engagement, daily consumption of vegetables/fruit, and group therapy attendance), or disease status (1st chemo-therapy, cancer recurrence and remission). Urinary symptoms were inversely related with age $(\rho=-.22, p<.05)$ with younger patients being more likely to report urinating more frequently than older patients. BMI, exercise, history of or recent surgery, and remission had clinically significant pain severity $(p<.05)$. Although the results suggest that urinary symptoms may correlate with cancer recurrence $(\rho=.22$, ns), the correlation was not significant.

Table 3 shows that poorer QoL scores correlated with having both surgery $(\rho=0.25, p<0.05)$ and first chemotherapy treatment $(\rho=0.22, p<0.05)$. Women who were older were less likely to have symptoms negatively impact their QoL than younger women $(\rho=-0.29, p<0.05)$. The more servings of fruits/vegetables $(p=-0.23, p<0.05)$, a woman consumed each day or the more frequently she engaged in exercise $(\rho=-0.20, p<0.05)$, the less likely she reported symptoms that negatively impacted her QoL. Those who were in remission were less likely to have their symptoms that affected their QoL $(\rho=-0.35, p<0.05)$.

Participants were more likely to have higher PWB scores and fewer complaints about fatigue if they were older $(\rho=0.31, p<0.05)$, engaged in exercise $(p=0.22, p<0.05)$, had daily intake of fruits/vegetables $(\rho=0.22, p<0.05)$, or were in remission $(\rho=$ $0.46, p<0.05)$. Having surgery $(\rho=-0.24, p<0.05)$, first chemotherapy $(\rho=-0.27, p<0.05)$, or recurrent cancer $(\rho=-0.23, p<.05)$ resulted in lower PWB. Support from friends and family as well as SWB score were positively correlated with age $(\rho=0.23)$. Older patients were more likely to have an increased sense of friends or family support than those who were younger. FWB had a positive association with age $(\rho=0.23, p<0.05)$, exercise $(\rho=0.23, p<0.05)$, and being in remission $(\rho=0.38, p<0.05)$. FWB was negatively correlated with cancer recurrence and positively correlated with exercise. Older patients had higher FWB scores than younger patients, and those who were in remission or did not have recurrence of cancer were more functional than their counterparts. 
Table 3 Spearman's Rho ( $\rho)$ Rank Correlations between Patient characteristics and pain, quality of life, social support and Wellbeing from April 2012 to July 2015

\begin{tabular}{|c|c|c|c|c|c|c|c|c|}
\hline \multirow{2}{*}{$\begin{array}{l}\text { Patient } \\
\text { Characteristics }\end{array}$} & & \multicolumn{3}{|c|}{ GUPI Symptoms } & \multicolumn{4}{|c|}{ FACT-G Well-Being } \\
\hline & & Pelvic Pain & $\begin{array}{l}\text { Urinary } \\
\text { symptoms }\end{array}$ & $\begin{array}{l}\text { Impact on } \\
\text { QoL }\end{array}$ & $\begin{array}{l}\text { Physical Well- } \\
\text { Being }\end{array}$ & $\begin{array}{l}\text { Social Well- } \\
\text { Being }\end{array}$ & $\begin{array}{l}\text { Emotional Well- } \\
\text { Being }\end{array}$ & $\begin{array}{l}\text { Functional Well- } \\
\text { Being }\end{array}$ \\
\hline \multirow[t]{2}{*}{ Age } & $P$ & 0.09 & $-.22^{\mathrm{a}}$ & $-.29^{\mathrm{a}}$ & $.31^{\mathrm{a}}$ & $.23^{\mathrm{a}}$ & 0.09 & $.23^{\mathrm{a}}$ \\
\hline & $N$ & 135 & 131 & 134 & 146 & 145 & 142 & 141 \\
\hline \multirow[t]{2}{*}{ BMI } & $P$ & 0.04 & -0.13 & 0.03 & 0.04 & 0.04 & -0.04 & 0.09 \\
\hline & $N$ & 120 & 116 & 119 & 121 & 121 & 118 & 117 \\
\hline \multirow[t]{2}{*}{ Exercise } & $P$ & 0.05 & -0.03 & $-.20 a$ & $.22^{\mathrm{a}}$ & 0.15 & 0.02 & $.23^{\mathrm{a}}$ \\
\hline & $N$ & 130 & 127 & 129 & 141 & 140 & 137 & 136 \\
\hline \multirow[t]{2}{*}{ Daily Fruit/Vegetables } & $P$ & 0.09 & 0.04 & $-.23^{c}$ & $.22^{\mathrm{a}}$ & 0.02 & 0.06 & 0.17 \\
\hline & $N$ & 127 & 123 & 126 & 127 & 127 & 124 & 124 \\
\hline \multirow[t]{2}{*}{ Support Group } & $P$ & 0.08 & -0.08 & -0.01 & -0.04 & -0.16 & -0.18 & -0.03 \\
\hline & $N$ & 134 & 130 & 133 & 145 & 144 & 141 & 140 \\
\hline \multirow[t]{2}{*}{ History/Recent Surgery } & $P$ & 0.05 & 0.10 & $.25^{\mathrm{a}}$ & $-.24^{\mathrm{a}}$ & -0.03 & 0.04 & -0.17 \\
\hline & $N$ & 133 & 129 & 132 & 144 & 143 & 140 & 139 \\
\hline \multirow[t]{2}{*}{ 1st Chemo } & $P$ & 0.13 & -0.05 & $.22 \mathrm{a}$ & $-.27^{\mathrm{a}}$ & -0.02 & 0.05 & -0.17 \\
\hline & $N$ & 108 & 106 & 107 & 119 & 118 & 116 & 115 \\
\hline \multirow[t]{2}{*}{ Recurrent Cancer } & $P$ & 0.08 & 0.22 & 0.16 & $-.23^{\mathrm{a}}$ & -0.09 & -0.19 & $-.24^{\mathrm{a}}$ \\
\hline & $N$ & 108 & 106 & 107 & 119 & 118 & 116 & 115 \\
\hline \multirow[t]{6}{*}{ Remission } & $P$ & 0.04 & -0.16 & $-.35^{\mathrm{a}}$ & $.46^{\mathrm{a}}$ & 0.10 & 0.14 & $.38^{\mathrm{a}}$ \\
\hline & $N$ & 108 & 106 & 107 & 119 & 118 & 116 & 115 \\
\hline & $N$ & 135 & 131 & 134 & 146 & 145 & 142 & 141 \\
\hline & M & 8.54 & 1.46 & 4.39 & 20.88 & 22.84 & 18.51 & 19.69 \\
\hline & $S D$ & 4.85 & 1.38 & 3.44 & 6.29 & 5.70 & 4.35 & 6.22 \\
\hline & $M d n$ & 9.00 & 1.00 & 4.00 & 23.00 & 24.50 & 19.00 & 20.00 \\
\hline
\end{tabular}

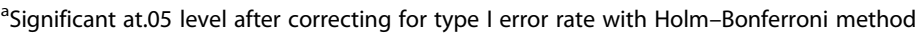

\section{Discussion}

Based on the survey results, we identified that age, pelvic pain, and lifestyle characteristics are indicators to poor HRQoL in women with gynecologic cancers. Previous studies have shown promise when investigating the influence of lifestyle on QoL in gynecologic cancers [22-25]. Lifestyle modifications have been shown to relieve fatigue, improve treatment induced anemia, maintain a healthy BMI, and enhance quality of sleep [26-28]. Our findings support this and indicate that weekly exercise ( $\geq 30 \mathrm{~min}$ of moderate activity) and a diet rich in fruits/vegetables ( $\geq 3$ servings per day) positively impacted HRQoL. Almost a quarter of our population did not partake in any physical activity. This is drastically different from previous research in breast and prostate cancer survivors who reported at least $>50 \%$ of physical activity [22, 29-32]. Inferences may be that our population and the studies characteristics were different. In those studies some patients were from higher socio-economic and education backgrounds, which may be different from our patient cohort, and it would be prudent to investigate these barriers in future studies.
Alarming, however, is the finding that $44 \%$ of our younger patients $\leq 60$ years of age reported having more issues with QoL. This is consistent with previous research among breast cancer and chronic disease patients. Younger patients have more issues adapting to their condition and have significant impairments in QoL, wellbeing, and recovery [13, 33-39]. Our data reinforces what other studies have found in chronic disease (Alzheimer's, Multiple Sclerosis, Bone, Breast, and Non-Small Cell Lung Cancer) and in gynecologic cancers such as Ovarian Cancer; that all patients especially those younger need to be targeted and counseled early in their care about the potential side effects in their disease and treatment [36, 40-47]. This has been shown to help patients have a more realistic expectation for their outcome, decrease patient anxiety, depression, and anticipate challenges that may lie ahead during and after their treatment. Multiple studies have shown that counseling patients on chemotherapy improved QoL and physiological and physical health scores when performed by a physician $[17,48]$.

Another principal finding was more then half of our sample reported clinically significant pelvic pain. BMI, 
exercise, history of or recent surgery, and remission had clinically significant pain. Pelvic pain is a distressing symptom and a common QoL concerns for women with gynecologic cancer, and may be an influential variable of QoL in Gynecologic malignancies [47, 48]. Our data supports that pelvic pain is a direct correlate of HRQoL.

This study is not without limitations. We conducted a cross-sectional convenience sample; therefore, our results may not be generalizable, especially since only two institutions were involved within this study. By limiting our respondents to women who only spoke English as a primary or secondary language, we may have excluded a portion of our population where cultural or language factors could have influenced our results. Although we sampled patients with different disease severity (first treatment, recurrent, or remission), selection bias is still possible, but given the nature of QoL concerns, radical difference across populations seems unlikely. We did not correlate symptoms based on specific gynecologic cancers and age, and no associations were made to see how the quality or location of pelvic pain varied within the study cohort. Finally, we have not yet investigated the responsiveness of this packet and its ability to detect baseline or important changes over time, even if that change is small.

\section{Conclusions}

This study identified potential areas of clinical focus, which aid in understanding our approach to caring for gynecologic cancer patients and improvement of their HRQoL. We identified that age, pelvic pain, and lifestyle characteristics have indicators to poor QoL in women with gynecologic cancers. In this population, younger women and those with pelvic pain complaints, poor diet and exercise habits should be targeted early for supportive care interventions to improve QoL throughout both treatment and survivorship.

\section{Highlights}

- Lifestyle interventions may be targeted towards specific populations to improve QoL in women with gynecologic cancers

- Further studies are needed to evaluate these effects on Health Related Quality of Life (HRQoL) in nonclinical trial patient population

\footnotetext{
Abbreviations

EMB: Emotional Wellbeing; FACT-G: Functional Assessment of Cancer Therapy-General; FWB: Functional Wellbeing; GUPI: Female Genitourinary Pain Index; HRQoL: Health-related quality of life; PRO: Patient Reported Outcome; PWB: Physical Wellbeing; QoL: Quality of Life; SWB: Social Wellbeing
}

\section{Acknowledgements}

Dr. Heather Dalton and Dr. Ekwutosi Okoroh for revising manuscript critically for important intellectual content and drafting the manuscript.
Availability of data and materials

Data sharing not applicable to this article as no datasets were generated or analyzed during the current study.

\section{Authors' contributions \\ DC and BM were involved in the conception and the design of the study. CC and SG took part in data collection. RR, DB, DC were responsible for data analysis and interpretation. DB, RR, SG were involved with drafting the manuscript or revisions for manuscript submission. DC and BM conceived the study design and participated in coordination and helped with the manuscript. All authors read and approved the final manuscript.}

Ethics approval and consent to participate

Not applicable

\section{Consent for publication}

Not applicable

\section{Competing interests}

The authors declare that they have no competing interests.

\section{Publisher's Note}

Springer Nature remains neutral with regard to jurisdictional claims in published maps and institutional affiliations.

\section{Author details}

${ }^{1}$ Department of Gynecologic Oncology, Creighton University School of Medicine at St. Joseph's Hospital and Medical Center, Phoenix, AZ, USA. ${ }^{2}$ University of Arizona Cancer Center, Tucson, AZ, USA.

Received: 29 November 2017 Accepted: 27 June 2018 Published online: 12 July 2018

\section{References}

1. Arriba LN, Fader AN, Frasure HE, von Gruenigen VE. A review of issues surrounding quality of life among women with ovarian cancer. Gynecol Oncol. 2010;119:390-6. https://doi.org/10.1016/j.ygyno.2010.05.014.

2. Pignata S, Ballatori E, Favalli G, Scambia G. Quality of life: Gynaecological cancers. Ann Oncol. 2001;12:37-42. https://www.researchgate.net/publication/ 11555496_Quality_of_life_Gynaecological_cancers (Accessed 19 Jan 2018).

3. Pearman T. Quality of life and psychosocial adjustment in gynecologic cancer survivors. Health Qual Life Outcomes. 2003;1:33. https://doi.org/10. 1186/1477-7525-1-33.

4. Doll KM, Barber EL, Bensen JT, Snavely AC, Gehrig PA. The health-related quality of life journey of gynecologic oncology surgical patients: implications for the incorporation of patient-reported outcomes into surgical quality metrics $\_$‘. Gynecol Oncol. 2016;141:329-35. https://doi.org/ 10.1016/j.ygyno.2016.03.003.

5. Moss HA, Havrilesky $\sqcup$. The use of patient-reported outcome tools in gynecologic oncology research, clinical practice, and value-based care, 2017. https://doi.org/10.1016/j.ygyno.2017.11.011.

6. Goker FKA, Guvenal T, Yanikkerem E. Turham, quality of life in women with gynecologic cancer in Turkey, Asian Pacific. J Cancer Prev. 2011;12:3121-8. https://www.researchgate.net/profile/Tevfik_Guvenal/publication/ 221680950_Quality_of_life_in_women_with_gynecologic_cancer_in_ Turkey/links/00b4953b6cbc00ed37000000.pdf (Accessed 10 Apr 2017

7. Guidozzi F. Living with ovarian Cancer. Gynecol Oncol. 1993;50:202-7. https://doi.org/10.1006/gyno.1993.1193.

8. Rannestad T, Skjeldestad FE, Platou TF, Hagen B. Quality of life among longterm gynaecological cancer survivors. Scand J Caring Sci. 2008;22:472-7. https://doi.org/10.1111/j.1471-6712.2007.00557.x.

9. Reis N, Beji NK, Coskun A. Quality of life and sexual functioning in gynecological cancer patients: results from quantitative and qualitative data. Eur J Oncol Nurs. 2010;14:137-46. https://doi.org/10.1016/j.ejon.2009.09.004.

10. Özaras G, Özyurda F. Quality of Life and Influencing Factors in Patients with a Gynaecologic Cancer Diagnosis at Gazi University, Turkey. Asian Pacific J Cancer Prev. 2010;11(5):1403-8. Article 45.

11. Wilailak S, Lertkhachonsuk A, Lohacharoenvanich N, Luengsukcharoen SC, Jirajaras M, Likitanasombat P, Sirilerttrakul S. Quality of life in gynecologic cancer survivors compared to healthy check-up women. J Gynecol Oncol. 2011;22:103. https://doi.org/10.3802/jgo.2011.22.2.103. 
12. Ersek M, Ferrell BR, Dow KH, Melancon $\mathrm{CH}$. Quality of life in women with ovarian Cancer. West J Nurs Res. 1997;19:334-50. https://doi.org/10.1177/ 019394599701900305.

13. Burckhardt CS, Anderson KL. The quality of life scale (QOLS): reliability, validity, and utilization. Health Qual Life Outcomes. 2003;1:60. https://doi. org/10.1186/1477-7525-1-60

14. Stover AM, Basch EM. Using patient-reported outcome measures as quality indicators in routine cancer care. Cancer. 2016;122:355-7. https://doi.org/10. 1002/cncr.29768

15. Basch E, Deal AM, Kris MG, Scher HI, Hudis CA, Sabbatini P, Rogak L, Bennett AV, Dueck AC, Atkinson TM, Chou JF, Dulko D, Sit L, Barz A, Novotny P, Fruscione M, Sloan JA, Schrag D. Symptom monitoring with patient-reported outcomes during routine Cancer treatment: a randomized controlled trial. J Clin Oncol. 2016;34:557-65. https://doi.org/10.1200/JCO.2015.63.0830.

16. Velikova G, Booth L, Smith AB, Brown PM, Lynch P, Brown JM, Selby PJ. Measuring quality of life in routine oncology practice improves communication and patient well-being: a randomized controlled trial. J Clin Oncol. 2004;22:714-24. https://doi.org/10.1200/JCO.2004.06.078.

17. Detmar SB, Muller MJ, Schornagel JH, Wever LDV, Aaronson NK. Healthrelated quality-of-life assessments and patient-physician communication. JAMA. 2002;288:3027. https://doi.org/10.1001/jama.288.23.3027.

18. Cella DF, Tulsky DS, Gray G, Sarafian B, Linn E, Bonomi A, Silberman M, Yellen SB, Winicour P, Brannon J. The Functional Assessment of Cancer Therapy scale: development and validation of the general measure. J Clin Oncol. 1993;11:570-9. http://www.ncbi.nlm.nih.gov/pubmed/8445433 (Accessed 18 July 2016)

19. von Gruenigen VE, Huang HQ, Gil KM, Frasure HE, Armstrong DK, Wenzel LB, The association between quality of life domains and overall survival in ovarian cancer patients during adjuvant chemotherapy: a gynecologic oncology group study. Gynecol Oncol. 2012;124:379-82. https://doi.org/10. 1016/j.ygyno.2011.11.032

20. Yost KJ, Thompson CA, Eton DT, Allmer C, Ehlers SL, Habermann TM, Shanafelt TD, Maurer MJ, Slager SL, Link BK, Cerhan JR. The Functional Assessment of Cancer Therapy - General (FACT-G) is valid for monitoring quality of life in patients with non-Hodgkin lymphoma. Leuk Lymphoma. 2013;54:290-7. https://doi.org/10.3109/10428194.2012.711830.

21. Clemens JQ, Calhoun EA, Litwin MS, McNaughton-Collins M, Kusek JW, Crowley EM, Landis JR. Urologic Pelvic Pain Collaborative Research Network, Validation of a modified National Institutes of Health chronic prostatitis symptom index to assess genitourinary pain in both men and women. Urology. 2009;74:983-7. https://doi.org/10.1016/j.urology.2009.06.078. NaN-3

22. Blanchard CM, Stein KD, Baker F, Dent MF, Denniston MM, Courneya KS, Nehl E. Association between current lifestyle behaviors and health-related quality of life in breast, colorectal, and prostate cancer survivors. Psychol Health. 2004;19:1-13. https://doi.org/10.1080/08870440310001606507.

23. Knols R, Aaronson NK, Uebelhart D, Fransen J, Aufdemkampe G. Physical exercise in Cancer patients during and after medical treatment: a systematic review of randomized and controlled clinical trials. J Clin Oncol. 2005;23: 3830-42. https://doi.org/10.1200/JCO.2005.02.148.

24. Courneya KS. Exercise in cancer survivors: an overview of research. Med Sci Sports Exerc. 2003;35:1846-52. https://doi.org/10.1249/01.MSS. 0000093622.41587.B6.

25. Bellizzi KM, Rowland JH, Jeffery DD, McNeel T. Health behaviors of cancer survivors: examining opportunities for cancer control intervention. J Clin Oncol. 2005;23:8884-93. https://doi.org/10.1200/JCO.2005.02.2343.

26. Ghavami $\mathrm{H}$, Akyolcu N. The impact of lifestyle interventions in breast Cance women after completion of primary therapy: a randomized study. J Breast Heal. 2017;13:94-9.

27. Mosher CE, Sloane R, Morey MC, Snyder DC, Cohen HJ, Miller PE, DemarkWahnefried W. Associations between lifestyle factors and quality of life among older long-term breast, prostate, and colorectal cancer survivors. Cancer. 2009;115:4001-9. https://doi.org/10.1002/cncr.24436.

28. Ravasco P, Monteiro-Grillo I, Marques Vidal P, Camilo ME. Impact of nutrition on outcome: a prospective randomized controlled trial in patients with head and neck cancer undergoing radiotherapy. Head Neck. 2005;27:65968. https://doi.org/10.1002/hed.20221.

29. Blanchard CM, Courneya KS, Stein K. American Cancer Society's SCS-II, Cancer survivors' adherence to lifestyle behavior recommendations and associations with health-related quality of life: results from the American Cancer Society's SCS-II. J Clin Oncol. 2008:26:2198-204. https://doi.org/10. 1200/JCO.2007.14.6217.
30. Maunsell E, Drolet M, Brisson J, Robert J, Deschênes L. Dietary change after breast cancer: extent, predictors, and relation with psychological distress. J Clin Oncol. 2002;20:1017-25. https://doi.org/10.1200/JCO.2002. 20.4.1017.

31. Meyerhardt JA, Heseltine D, Niedzwiecki D, Hollis D, Saltz LB, Mayer RJ, Thomas J, Nelson H, Whittom R, Hantel A, Schilsky RL, Fuchs CS. Impact of physical activity on cancer recurrence and survival in patients with stage III colon cancer: findings from CALGB 89803. J Clin Oncol. 2006;24:3535-41. https://doi.org/10.1200/JCO.2006.06.0863.

32. Doyle C, Kushi LH, Byers T, Courneya KS, Demark-Wahnefried W, Grant B, McTiernan A, Rock CL, Thompson C, Gansler T, Andrews KS. 2006 nutrition, physical activity and Cancer survivorship advisory committee, American Cancer Society, nutrition and physical activity during and after cancer treatment: an American Cancer Society guide for informed choices. CA Cancer J Clin. n.d.56:323-53. http://www.ncbi.n/m.nih.gov/pubmed/ 17135691 (Accessed 20 Jan 2018)

33. Avis NE, Crawford S, Manuel J. Quality of life among younger women with breast cancer. J Clin Oncol. 2005;23:3322-30. https://doi.org/10.1200/JCO. 2005.05.130.

34. Wenzel LB, Fairclough DL, Brady MJ, Cella D, Garrett KM, Kluhsman BC, Crane LA, Marcus AC. Age-related differences in the quality of life of breast carcinoma patients after treatment. Cancer. 1999;86:1768-74. http://www. ncbi.n/m.nih.gov/pubmed/10547550 (accessed January 20, 2018)

35. Canuet L, Ishii R, Iwase M, Ikezawa K, Kurimoto R, Azechi M, Takahashi H, Nakahachi T, Teshima Y, Takeda M. Factors associated with impaired quality of life in younger and older adults with epilepsy. Epilepsy Res. 2009;83:5865. https://doi.org/10.1016/J.EPLEPSYRES.2008.09.001.

36. Brod M. Pilot study - quality of life issues in patients with diabetes and lower extremity ulcers: patients and care givers. Qual Life Res. 1998;7:36572. https://doi.org/10.1023/A:1024994232353.

37. Bifulco G, De Rosa N, Tornesello ML, Piccoli R, Bertrando A, Lavitola G, Morra I, Di A, Sardo S, Buonaguro FM, Nappi C. Quality of life, lifestyle behavior and employment experience: a comparison between young and midlife survivors of gynecology early stage cancers. Gynecol Oncol. 2012;124:44451. https://doi.org/10.1016/j.ygyno.2011.11.033.

38. Paraskevi T. Quality of life outcomes in patients with breast cancer. Oncol Rev. 2012;6:e2. https://doi.org/10.4081/oncol.2012.e2.

39. Wenzel L, Vergote I, Cella D, Quality of Life in Patients Receiving Treatment for Gynecologic Malignancies: Special considerations for patient care, (n.d.). http://www.unipd.it/esterni/wwwginec/AssistenzaDocumenti/Unita'\%20operative/Ginecologia\%200ncologica/B5\%20\%20QUALITY\%200F\%20LIFE.pdf (Accessed 6 May 2018).

40. Howell D, Fitch MI, Deane KA. MN Institution: From the Psychosocial and Behavioral Research Unit, Toronto Sunnybrook Regional Cancer Centre, Toronto Ontario. Impact of Ovarian Cancer Perceived by Women. Cancer Nurs. 2003;26(1):1-9.

41. Armstrong DK. Disease Relapsed Ovarian Cancer: Challenges and Management Strategies for a Chronic Relapsed Ovarian Cancer: Challenges and Management Strategies for a Chronic Disease, 2002. doi:https://doi.org/ 10.1634/theoncologist.7-suppl_5-20.

42. Sørensen LV, Waldorff FB, Waldemar G. Early counselling and support for patients with mild Alzheimer's disease and their caregivers: a qualitative study on outcome. Aging Ment Health. 2008;12:444-50. https://doi.org/10. 1080/13607860802224342.

43. Fawzy Fl, Fawzy NW, Hyun CS, Elashoff R, Guthrie D, Fahey JL, Morton DL. Malignant Melanoma. Arch Gen Psychiatry. 1993;50:681. https://doi.org/10. 1001/archpsyc.1993.01820210015002.

44. Temel JS, Greer JA, Muzikansky A, Gallagher ER, Admane S, Jackson VA, Dahlin CM, Blinderman CD, Jacobsen J, Pirl WF, Billings JA, Lynch TJ. Early palliative Care for Patients with metastatic non-small-cell lung Cancer. N Engl J Med. 2010;363:733-42. https://doi.org/10.1056/NEJMoa1000678.

45. Felder-Puig R, Formann AK, Mildner A, Bretschneider W, Bucher B, Windhager R, Zoubek A, Puig S, Topf R. Quality of life and psychosocial adjustment of young patients after treatment of bone cancer. Cancer. 1998; 83:69-75. https://doi.org/10.1002/(SICI)1097-0142(19980701)83:1<69::AIDCNCR10>3.0.CO;2-A.

46. Periasamy U, Mohd Sidik S, Rampal L, Fadhilah SI, Akhtari-Zavare M, Mahmud R. Effect of chemotherapy counseling by pharmacists on quality of life and psychological outcomes of oncology patients in Malaysia: a randomized control trial. Health Qual Life Outcomes. 2017:15:104. https:// doi.org/10.1186/s12955-017-0680-2. 
47. Craig C, Gibson S, Osann K, Farley J, Monk B, Chase D. Pelvic pain, quality of life (QOL), and exercise in gynecologic cancer patients: a single institution study. Gynecol Oncol. 2013;130:e31-2. https://doi.org/10.1016/j.ygyno.2013.04.135.

48. Honerlaw KR, Rumble ME, Rose SL, Coe CL, Costanzo ES.

Biopsychosocial predictors of pain among women recovering from surgery for endometrial cancer. Gynecol Oncol. 2016;140:301-6. https://doi.org/10.1016/j.ygyno.2015.09.005.

Ready to submit your research? Choose BMC and benefit from:

- fast, convenient online submission

- thorough peer review by experienced researchers in your field

- rapid publication on acceptance

- support for research data, including large and complex data types

- gold Open Access which fosters wider collaboration and increased citations

- maximum visibility for your research: over $100 \mathrm{M}$ website views per year 